\title{
Priori Incantatem: uma discussão sobre a colonização do imaginário no larp blockbuster $^{1}$
}

\section{Jorge Miklos}

Doutor, Universidade Paulista, São Paulo, SP, Brasil

jorgemiklos@gmail.com

\section{Tadeu Rodrigues Luama ${ }^{2}$}

Doutorando, Universidade Paulista, São Paulo, SP, Brasil

tadeu.rodrigues@edu.uniso.br

\section{Resumo}

O presente artigo tem por tema a relação do larp com os Estudos do Imaginário, sobretudo naqueles que têm recebido maior cobertura midiática, que podem ser chamados de larps blockbusters. A partir desse recorte, é discutida uma potencial colonização do Imaginário pela cooptação mercadológica dessa mídia. Para tanto, utiliza-se, sobretudo, os conceitos de mediosfera, vínculos hipnógenos e o potencial transcendente da comunicação por meio de uma revisão bibliográfica que dialoga com estudo de caso.

\section{Palavras-chave}

Comunicação. Imaginário. Mediosfera. Estudo de caso. Larp.

\section{Introdução}

Um grupo de pessoas se reúne. Por algumas horas, eles deixarão de lado suas personalidades cotidianas. Algumas vezes, estarão vestidos a caráter. Outras, contarão apenas com a imaginação. 0 entorno é reconfigurado: uma sala de estar, na realidade, pode se tornar a antecâmara de um tribunal, na ficção. Juntos, irão agir e se relacionar de maneira distinta: desempenharão papéis. Como personagens fictícias, a intenção desse encontro é criar narrativas conjuntamente, de maneira espontânea. A presença de uma audiência não é desejada: melhor seria se essas pessoas também adentrassem na experiência. Se você já

\footnotetext{
${ }^{1}$ Versão de trabalho de mesma autoria apresentado no 40 CONGRESSO BRASILEIRO DE CIÊNCIAS DA COMUNICAÇÃO, 2017.

${ }^{2} 0$ presente trabalho foi realizado com apoio da Coordenação de Aperfeiçoamento de Pessoal de Nível Superior - Brasil (CAPES) - Código de Financiamento 001
} 
brincou de casinha, pode ter uma ideia do que essa cena descreve. Mas esse grupo de pessoas se reuniu para participar de um larp.

O larp (live action role playing, ou desempenho de papéis ao vivo) é uma prática lúdica que, embora seja chamado assim há quase 50 anos, por vezes ainda é vista com olhares de ineditismo (inclusive pelas pesquisas de Comunicação no Brasil). Consiste no desempenho de papéis, de maneira presencial, com o intuito de vivenciar uma narrativa que é tecida espontaneamente, por meio das relações entre os participantes, sem roteiro prévio. Ressonante à cultura Do It Yourself, ou Faça Você Mesmo, é frequentemente organizado por grupos de amigos, embora também seja proposto por pessoas engajadas com essa prática para um espectro maior de participantes ${ }^{3}$. Parte de uma perspectiva inclusiva: qualquer indivíduo pode participar de um larp, sem necessidade de alguma formação técnica anterior. Além disso, historicamente, é uma prática que tende à gratuidade ${ }^{4}$.

Por conta disso, a indagação que este artigo objetiva refletir é acerca de quais implicações poderiam decorrer da apropriação mercantil de tal prática. Para tanto, tomamos como aporte metodológico a revisão de literatura, circundante a um estudo de caso que consideramos emblemático e passível da aplicação do princípio hologramático da complexidade (MORIN, 2007): não apenas a parte está inserida no todo, mas também o todo está inserido na parte. Dessa forma, olhar para um caso específico poderia fornecer importantes pistas acerca de um panorama.

Em outras palavras, é como a brincadeira de faz de conta (também conhecida como jogo simbólico). Contudo, como envolve mais de um participante, as relações entre os diferentes mundos imaginados pelos diferentes participantes evocam uma complexidade maior: diferentemente do consumo de narrativas cristalizadas, em que o espaço do consumidor é somente a interpretação do texto imutável concebido pelo produtor, aqui existe uma sobreposição de diferentes concepções (e percepções) narrativas, que interagem e alteram umas às outras.

Num primeiro momento, o larp poderia ser confundido com o teatro. Porém, a ausência de enredo, e, em grande parte das vezes, de direção, faz com que possamos tratar como uma manifestação artística distinta. Mesmo em teatros mais voltados ao improviso, ou mesmo quando comparamos com a performance, existe uma diferença substancial: o larp não admite uma audiência passiva ou, em outras palavras, "a principal diferença é que ele não é para ser visto... é para ser vivido" (FALCÃO, 2013, p. 17). Todos os participantes são

\footnotetext{
${ }^{3}$ A título de exemplo, destacamos a ocorrência frequente de larps em diversas unidades do SESC-SP, assim como a atuação da ONG Confraria das Ideias junto a bibliotecas públicas e centros culturais na cidade de São Paulo.

${ }^{4}$ Por vezes, os custos de organização, tais como cenografia, são previamente rateados em comum acordo dos participantes de produções mais robustas.
} 
agentes da experiência. Essa característica altera o centro da experiência: em vez de representar para uma plateia, os participantes representam apenas para si mesmos e uns para os outros, e com isso desmantelam quaisquer hierarquias que porventura possa haver entre artista e público.

O larp também possui elementos lúdicos. Existe um parentesco inerente entre os larps e os RPGs (Role Playing Games, ou jogos de desempenho de papéis). A principal diferença entre ambos consiste no fato do larp envolver a ação do corpo, enquanto o RPG envolve apenas a descrição das ações feitas. Contudo, as semelhanças são muitas, de modo que alguns autores (MONTOLA, 2014; POHJOLA, 2014) utilizam o termo RPG para designar uma família de práticas que inclui tanto os larps quantos os RPGs de mesa (tabletop RPG, ou tRPG). Esse elemento lúdico existente no larp pode ser visto tanto na agência que existe entre os participantes quanto no caráter de lazer geralmente ligado à atividade.

\section{Trajetória do larp}

Embora a definição dessa prática possa remontar a atividades muito antigas da humanidade, tais como os ritos que nossos ancestrais primevos praticavam, o uso do termo, embora sem data certa, é cunhado por volta da década de 1970. A partir de então, notamos que a trajetória do larp pode ser observada em três movimentos distintos.

Em um primeiro movimento, os larps preocupam-se, especialmente, com tornar possível a ideia de protagonismo para grupos de aficionados em literatura e outros produtos da cultura popular, principalmente de temática fantástica. Podemos inferir a relação dessa prática com o conceito de antropofagia, uma vez que envolvem a assimilação de conteúdos externos e a ressignificação desses conteúdos (SILVA, 2007). Dessa maneira, podemos observar que, nas primeiras décadas (e com origem geográfica incerta), seus participantes tinham como meta, na maior parte das vezes, trazer conteúdos de suas ficções favoritas e aglutinar eles com outras ficções ou outros contextos. Mais do que isso, a premissa de ser o protagonista da história atraía participantes que queriam viver as aventuras de suas ficções favoritas, ou ainda tomar decisões diferentes das tomadas por suas personagens favoritas. Em suma, nesse primeiro movimento, os larps tiveram uma forte associação ao que comumente é denominado fandom, uma comunidade de pessoas pautada pelos gostos comuns.

Posteriormente, já no final da década de 1990, um segundo movimento pode ser identificado, iniciado na Noruega, Dinamarca, Suécia e Finlândia. Nesses quatro países, têmse o debate de explorar outras potencialidades do larp, além das manifestações próximas de fanfics (termo que retrata as ficções feitas por fãs, derivadas de uma obra original). Por conta 
disso, abre-se o debate para o reconhecimento do larp enquanto mídia e expressão artística autônoma. 0 termo autônoma é utilizado em função do reconhecimento de algo além de uma forma de teatro ou similares. Por conta disso, afloram os debates do que poderia ser caracterizado como inerente (ou exclusivo) ao larp. Em decorrência da vanguarda dos países citados, geralmente os larps com esse cunho são conhecidos como nórdicos, e podemos perceber que nesses geralmente ocorre o desprendimento com as obras derivadas e buscase a originalidade e a experimentação. É importante frisar que cada um desses movimentos não é excludente, mas sim cumulativo: o surgimento dos larps nórdicos não implica o desaparecimento daqueles com maior adesão às fanfics. Ainda hoje, uma grande parte dos larps possui a mesma configuração e temática dos primeiros larps documentados.

Os estudos sobre larp também demonstram um aumento significativo a partir desse período. A primeira pesquisa que tangencia o tema (o foco da pesquisa é o RPG de mesa) é um estudo estadunidense de 1983, que realiza uma etnografia das comunidades de jogadores (FINE, 2002). Contudo, a partir de 1997, surge a conferência nórdica anual (chamada Knutepunkt na Noruega, Knutpunkt na Suécia, Knudepunkt na Dinamarca e Solmukohta na Finlândia), que circula entre os quatro países. Porém, com o passar dos anos, a conferência internacionalizou-se, contando hoje com participantes de diversos países. Ao contrário de grande parte das outras conferências proferidas cuja ênfase é a prática do larp, a Knutepunkt surge com o estímulo ao debate, e ainda hoje pode ser vista como um dos pontos de referência para saber o que está sendo pesquisado sobre o tema ao redor do mundo. Parte disso dá-se pela tradição da conferência publicar ao menos um livro anualmente (e, além da versão impressa, disponibilizar versão digital gratuitamente) desde 2003 e adotar o uso do inglês como língua franca.

Por último, notamos um terceiro movimento, no qual a capitalização do larp parece ser uma característica inerente. Não se trata do envolvimento do dinheiro na prática do larp, uma vez que, desde os primórdios, larps com produções mais robustas sempre envolveram custos. Trata-se de conglomerados econômicos voltando suas atenções para o larp, tais como a Disney Enterprises, grupo empresarial composto por The Walt Disney Company, Marvel Entertainment, Lucasfilm, o canal de televisão ABC, entre outros. Em 2011, Disney Enterprises arquivou um pedido de patente para uma estrutura de simulação de role-play (KALAMA et al., 2013), e a descrição da patente, embora não utilize o termo larp, é análoga ao mesmo em diversos pontos. Em 2017, a mesma companhia anuncia um novo parque, com inauguração prevista para 2019, com temática da franquia Star Wars (SAVVAS, 2017). As atrações do parque ainda se encontram no campo da especulação, mas as notícias orbitam em torno de atividades que envolvam interação e engajamento por parte dos visitantes e um 
resort temático onde cada hóspede irá desempenhar um papel na trama proposta pelo parque (JASPER, 2017). De acordo com Jasper (2017), Asa Kalama está entre os responsáveis pelo projeto. Kalama, diretor executivo criativo da Walt Disney Imagineering, é um dos inventores listados no pedido de patente citado anteriormente.

Não é surpresa que a Walt Disney Imagineering, braço de pesquisa e desenvolvimento da Disney, tenha demonstrado tanto interesse pelos larps. Um dos Dez mandamentos do Mickey (conjunto de princípios que regem a empresa) envolve a participação. A ênfase fica evidente no discurso de uma oficina, ministrada em 1991:

[...] 0 ponto importante... é a participação. Quando vocês pensam sobre isso, nós recebemos uma enorme parte das nossas experiências como espectadores passivos... Isso é o que faz lugares como Disneyland, Walt Disney World e Tokyo Disneyland tão especiais; isso é o que nos coloca num relacionamento diferente dos livros ou meios passivos. Nós damos às pessoas a oportunidade de realmente exercitar seus sentidos. 0 melhor de todos os mundos é quando o público pode tocar algo - participar. Se eles podem tocá-los você certamente poderá tocá-los. (PAPERS, 1991, p. 18, tradução nossa).

Se para a Disney Enterprises a relação com o larp oscila entre a especulação e o flerte, algumas iniciativas já estão em movimento. Dentro dos limites deste artigo, pretendemos exemplificar com uma delas.

\section{De Harry Potter a College of Wizardry}

A franquia Harry Potter, concebida pela escritora britânica J. K. Rowling, conta com 10 livros (sete compondo a trama principal, que também são disponíveis como audiolivros e três obras derivadas), 10 adaptações cinematográficas (oito referentes à trama principal e duas adaptações de obra derivada), o parque temático The Wizarding World of Harry Potter, 11 jogos eletrônicos (oito adaptações dos livros/filmes e três obras derivadas) e uma peça de teatro. A história do jovem bruxo figura entre as franquias mais rentáveis do século XXI.

Além das obras de caráter oficial, a franquia conta com um número expressivo de fanfics, a ponto de ser utilizada por Henry Jenkins como espinha dorsal de um capítulo que debate o tema. De acordo com Jenkins (2009), o fandom de Harry Potter apresenta tamanha articulação que consegue criar enfrentamentos com a Warner Bros. Entertainment (detentora dos direitos da série) em questões relativas a direitos autorais. Recentemente, a empresa apresentou um novo recuo nessa questão, ao ceder o aval para produção de um filme feito por fãs (FRANKLIN, 2017). 
No outro polo da questão, temos o dinamarquês Claus Raasted, um dos mais proeminentes nomes da cena nórdica de larp, atuando como organizador de larps, editor e organizador de convenções desde a década de 1990. Preside duas companhias (Rollespilsfabrikken e Rollespilsakademiet) há mais de dez anos. Recentemente, suas duas companhias associaram-se à companhia polonesa Liveform para fundar o coletivo Dziobak Larp Studios, de atuação internacional, com membros de sua equipe sediados na Dinamarca, Polônia, Alemanha, Romênia e Canadá (DZIOBAK, 2017). Ao observarmos o fenômeno das fanfics de Harry Potter, aliado à tendência antropofágica identificada nos larps, imaginar larps situados no mundo concebido por Rowling seria uma dedução lógica. É impossível documentar quantos larps foram realizados utilizando essa obra como pano de fundo, uma vez que a horizontalidade e informalidade inerente a essa prática faz com que diversos grupos que decidiram realizar esses larps sejam, e permaneçam, desconhecidos. Porém, nesse contexto, a obra de Raasted destaca-se.

Desde 2014, Raasted é organizador do College of Wizardry (CoW). De acordo com o press release da empresa (DZIOBAK, 2016), o primeiro CoW surgiu:

\footnotetext{
Quando um grupo de larpers da Dinamarca e Polônia decidiram investir seus recursos e tempo, escrever uma história inspirada pelos livros de J. K. Rowling e convidar mais de 100 participantes para o castelo do século XIII de Czocha para dar a eles a experiência única de participar de uma escola de magia. (DZIOBAK, 2016, p. 1, tradução nossa).
}

Em 2016, o larp estava em sua décima edição, tendo contado até então com mais de 1.000 participantes originários de 30 países diferentes, com mais quatro edições esperadas para 2017 (DZIOBAK, 2016). Conta também com a CzochaBook, uma plataforma similar ao Facebook criada para os participantes do larp. Apesar de ter ingressos que variam entre 210 e 680 Euros (COLLEGE..., 2017), as duas primeiras edições de 2017 já estavam esgotadas antes mesmo da última edição de 2016 (DZIOBAK, 2016). Ressaltamos que, depois das três primeiras versões, o CoW foi obrigado a deixar de referenciar diretamente o universo de Harry Potter, devido a um acordo com a Warner Bros. Entertainment (RAASTED, 2016), embora permaneça fortemente enraizado na franquia, a ponto de as influências serem claras.

Esse é o contexto no qual realizamos nosso diálogo sobre o assunto. Evidencia-se (IUAMA, 2018) a configuração de um processo comunicacional nos jogos narrativos. Em suma, esse processo seria caracterizado por dois movimentos distintos: uma relação entre o indivíduo e sua imaginação; e uma relação entre os indivíduos. Ou, como aponta o pesquisador finlandês Markus Montola (2003), uma construção interativa de mundos 
ficcionais subjetivos. Dessa forma, o processo compreende tanto a construção imaginária de cada mundo de jogo por cada indivíduo quanto as interferências dadas pelas relações entre eles durante um larp.

Nesse âmbito, apontamos para uma relação entre o larp e o imaginário, uma vez que esses mundos ficcionais subjetivos são colocados em relação, e o caráter arquetípico do imaginário garantiria um solo comum para que as interações entre os indivíduos ocorram. Contudo, o mesmo arquétipo pode se manifestar por diversas imagens (JUNG, 2000), de modo que é esperado que cada participante encerre o larp com uma interpretação única dos eventos ocorridos durante ele. Isso se daria, em grande parte, graças às diversas possibilidades de interpretação de um mesmo ato simbólico, dependendo do repertório de cada um. Uma vez que o larp é uma atividade com grande aderência aos rituais (BOWMAN, 2010), podemos pensar que comunicação é vínculo e a religião seria uma forma primeira de vínculo (MIKLOS, 2010). Dessa maneira:

\begin{abstract}
A experiência religiosa (religações) é vivenciada nos rituais, que na maioria visam à transcendência e que por isso tem como principal plataforma o corpo. Não poderia ser de outra forma, já que não se pode conceber a transcendência sem a experiência da imanência, ou seja, só é possível transcender a partir de uma realidade espaço-temporal específica. (MIKLOS, 2012, p. 67).
\end{abstract}

No âmbito desse processo comunicacional, indagamos: quais seriam as implicações da interferência (mercado)lógica nesse ato com significativos entrecruzamentos com o imaginário?

Nosso ponto de partida para essa problematização é a mediosfera. 0 conceito, formulado por Malena Contrera (2017), surge a partir da noosfera moriniana (MORIN, 1998), que postula uma realidade objetiva ${ }^{5}$, porém não física, povoada pelo imaginário, de caráter arquetípico (JUNG, 2000). Já a mediosfera seria uma versão perversa da noosfera, construída a partir da cooptação dos símbolos pelo capitalismo, por meio dos conteúdos midiáticos, esvaziando-os de sentido- o que é paradoxalmente causado pelo excesso ${ }^{6}$.

O elemento simbólico dos larps pode ser visto inclusive pelo viés terapêutico (BOWMAN, 2017), uma vez que o participante passa a se relacionar com conteúdos psíquicos que, de outra forma, talvez estivessem tamponados. Ao ser usurpado por interesses (mercado)lógicos, esse potencial de comunicação transcendente dos larps deixa de ter contato com a noosfera, passando assim a ser aliciado para a mediosfera.

\footnotetext{
${ }^{5}$ Reforça-se o caráter objetivo dado à noosfera por Morin, uma vez que não se trata de uma concepção do indivíduo (subjetiva).

${ }^{6}$ Sobre os excessos midiáticos, sugerimos a ampliação do tema com o conceito de pânico, igualmente abordado pela autora (CONTRERA, 2002).
} 
Uma vez que assumimos comunicação como vínculo, poderíamos pensar nessa comunicação vampirizada pela mediosfera como constituinte de vínculos hipnóticos/hipnógenos. Esses vínculos “[...] caracterizam-se não somente pela resposta literal ao comando estabelecido, mas também por esta ação basear-se em forte poder de comando do hipnotizador para com o hipnotizado" (SILVA; BAITELLO JUNIOR, 2013, p. 6).

A distinção entre hipnotizador e hipnotizado pode parecer descolada de uma atividade horizontalizada e participativa, como é o caso dos larps. Contudo, ao observarmos o grau técnico de um larp como o $\operatorname{CoW}$ (Figura 1), realizado em um castelo, com figurinos vultosos, passa a existir uma hierarquização entre um produtor e um consumidor. A própria comunidade de larp ao redor do mundo tem utilizado termos como larp blockbuster (em referência aos filmes de grande orçamento da indústria cinematográfica de Hollywood) ou larp tourism (larp turismo, similar ao turismo de parques de diversões).

Figura 1 - College of Wizardry, 2017.

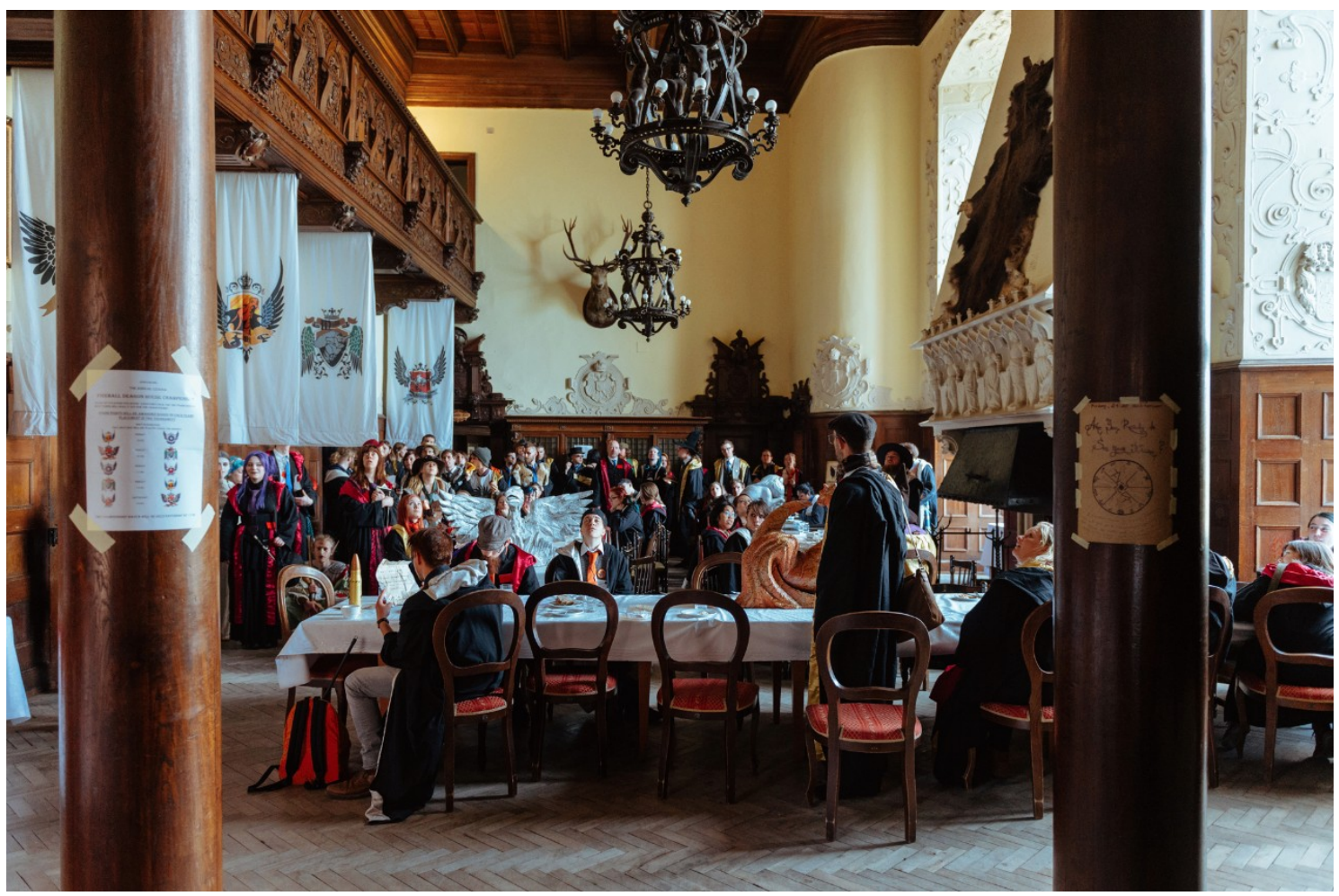

Fonte: College of Wizardry. ${ }^{7}$

Destarte, poderíamos considerar esse fenômeno - em oposição etimológica ao simbolismo inerente à linguagem do larp - como diabólico, uma vez que apartaria o indivíduo de uma experiência de comunhão com seus próprios conteúdos psíquicos, substituídos por um conteúdo midiatizado.

\footnotetext{
${ }^{7}$ Disponível em: https://goo.gl/fvemGV. Acesso em: 05 jul. 2017.
} 
Observamos que o vínculo hipnógeno:

[...] estabelece-se no contexto midiático (mediosfera), fundado na construção de imagens técnicas fugazes que obedecem cegamente aos programas, dentre eles o programa cristalizado dos papéis de emissor e receptor. Caracteriza-se este último pela ludicidade exacerbada (cega e obediente), isto é, pela finalidade em si mesma e pela ilusão (in ludere), por parte do receptor, de que ao agir sobre o aparelho atua como emissor. (SILVA; BAITELLO JUNIOR, 2013, p. 6).

A relação entre o larp blockbuster e a hipnogenia/mediosfera pode parecer demasiada apocalíptica em um primeiro momento. Porém, se voltarmos nossas atenções novamente à Disney, poderemos notar que seu departamento de pesquisa e desenvolvimento é chamado Imagineering, conforme pontuamos anteriormente. 0 termo, propriedade intelectual da companhia, é uma junção de imagination (imaginação) e engineering (engenharia). Se pensarmos na ideia de uma engenharia da imaginação, e ela estiver alinhada com o departamento de pesquisa e desenvolvimento de um dos maiores conglomerados de mídia e entretenimento do mundo, uma colonização do imaginário parece uma realidade palpável.

\section{0 feitiço virou contra o feiticeiro?}

Priori Incantatem foi o título escolhido para este estudo. Oriundo da franquia Harry Potter, o termo representa o feitiço reverso, ou seja, a volta do último feitiço lançado para o feiticeiro que o lançou (ROWLING, 2001). Pareceu-nos adequado associar isso ao larp blockbuster. Se o larp inicia com uma antropofagia criada por culturas identificadas como fandom, a posterior exploração da linguagem abre novas oportunidades e expande os limites. Em dado momento, a experimentação era tamanha a ponto de haver problematizações sobre a necessidade de um zumbi ${ }^{8}$ (PETTERSSON, 2011). Quando o larp passa a ganhar relevância econômica, parece que o apelo causado junto ao fandom de obras derivadas reverte essa prática à sua versão primeira, como pertencente ao universo das fanfics, porém agora munida de uma produção mais robusta, cooptada durante anos de exploração de potencialidades da linguagem.

Se pensarmos que o larp é uma expressão artística, uma mídia e/ou uma linguagem, os mais variados larps são abarcados, inclusive os blockbusters. Contudo, a problematização

\footnotetext{
${ }^{8} 0$ termo zumbi aqui é utilizado como sinônimo de atrativo, tomando por exemplo séries que envolvem zumbis, que podem até ser sobre outro tema, mas utilizam zumbis para atrair o público. Grosso modo, zumbi necessário é um jargão no larp 
que procuramos evidenciar neste estudo é a colonização que ocorre durante esse processo. Observamos que o larp, dificilmente noticiado para o grande público, tem recebido maior atenção nos últimos anos. 0 impacto que um veículo como o The Guardian (FORSTER, 2016) teria ao demonstrar o larpCoW para um público que não teve contato anterior com a linguagem poderia reduzir o larp ao universo da fanfic novamente, mesmo após anos de pesquisa e desenvolvimento para retirá-lo desse escopo. Ao mesmo tempo em que existem críticas a tal movimento (FATLAND, 2017), a ideia tem se expandido. Larps baseados em séries de televisão - como Downtown Abbey (FAIRWEATHER, 2015) ou Battlestar Galactica (KARLSSON, 2013), ou na literatura da escritora inglesa Jane Austen (1775-1817), autora de livros como Orgulho \& Preconceito (FORTUNE, 2017) -têm povoado cada vez mais o cenário internacional, sempre associados a produções suntuosas.

Contudo, tais larps derivados de outras obras têm conquistado uma gama de consumidores que torna a atividade atrativa (mercado) logicamente. 0 próprio College of Wizardry já encontra hoje obras que derivam dele. Nos Estados Unidos, a New World Magischola (NWM) está em sua sexta versão (NEW..., c2017). Na Alemanha, a Nibelungen Institute für Magische Bildungund Studien (NIMBUS) debutou em 2017 (MOCHOCKI, 2016). Ambas compartilham com o CoW o mesmo mundo ficcional, fruto a ser explorado em versões que incluam o crossover das três escolas, em alusão clara ao Torneio Tribruxo presente em Harry Potter (ROWLING, 2001).

No Brasil, o produto chegou em 2016 (ESCOLA..., 2017). Sem nenhum contato com o CoW, mas ainda assim com a mesma proposta, a Escola de Magia e Bruxaria (EMB) apresenta um custo até maior do que a versão europeia, sem levar em conta as iniquidades econômicas entre os dois locais. Tais quais as referências diretas a Harry Potter, as referências diretas ao larp foram apagadas, e talvez essa seja o maior indício de uma apropriação (mercado)lógica. Nesse processo de colonização, as notícias sobre a $E M B$, propagadas por veículos como a Veja São Paulo (ÖBERG, 2016) e Folha de São Paulo (EM CAMPOS..., 2017), em nenhum momento mencionam o termo larp. E por que deveriam?

\section{Discussão}

A discussão teórica do que chamamos de apropriação do larp pela indústria cultural tem como referencial teórico as teses enunciadas por Serge Grunzinski (2003) em seu livro A colonização do imaginário: sociedades indígenas e ocidentalização do México espanhol.

Serge Grunzinski (2003) postula que o imaginário não é irreal, distante do empírico, do mundo sensível. Para Grunzinski (2003), o imaginário está em relação com o mundo real 
e com as experiências cotidianas, mas, ao mesmo tempo, não se prende somente a elas. 0 imaginário é uma dimensão na qual as sociedades constroem sua forma e através da qual elas enxergam o mundo e a si mesmas. É na esfera do imaginário que existem os problemas de ordem histórica e antropológica. 0 imaginário é composto, de forma bastante geral, de elementos que dão sentido e valor às nossas experiências sensíveis. Todas as sociedades, e mesmo os grupos que as compõem, possuem seus imaginários - imaginários sobre si e sobre os outros, questão indispensável no trato entre as culturas.

Os seres humanos criam significado interagindo com seu ambiente natural e social, conectando suas redes neurais com as redes da natureza e com as redes sociais. A constituição de redes é operada pelo ato da comunicação. Comunicação é o processo de compartilhar significado pela troca de informações. Para a sociedade em geral, a principal fonte da produção social de significado é o processo da comunicação socializada.

Nesse aspecto, Grunzinski (2003) trata do problema da dominação do México a partir daquilo que ficou velado, o que ocorreu com a forma de ver o mundo dos nativos da América após a chegada do europeu. Para isso, ele relaciona elementos que apontam para essas transformações: a cristianização do México e as transformações nas formas de linguagem nativa:

Frequentemente, o papel crucial que a imagem desempenhou na conquista da América e, em particular, do México, é negligenciado. Sem incorrer em anacronismos e falar em "guerra de imagens", há que se reconhecer que o Ocidente utilizou nesse período a maioria dos recursos visuais de que se dispunha no século XVI, com intuito de apoiar seu projeto de dominação. (GRUZINSKI, 2003, p. 198).

O teor da discussão de Grunzinski (2003), aponta para ocidentalização da linguagem nativa. Para ele, a mentalidade indígena foi transmutada pelo cristianismo, houve uma transformação na "visão de mundo e na concepção de sentido" após a inserção da linguagem europeia nos povos nativos.

Cortez teria levado para o México a tradição de Nossa Senhora de Guadalupe, cuja origem remontava ao século VIII na Espanha, tendo substituído a deusa da Lua dos Maias pela imagem da Virgem Maria. Dessa forma, a ocidentalização da América foi uma guerra de imagens, em que a Igreja Católica abordou as grandes civilizações ameríndias desconhecidas, sofisticadas e desconcertantes, sob o ângulo das imagens. Para a Igreja Católica, essas sociedades praticavam uma falsa religião: a idolatria centrada no culto às representações "falsas", através da veneração da "imagem sem fundamentos", inspiradas, 
segundo eles, pelo Diabo. Portanto, a cristianização deveria localizar, detectar e destruir sistematicamente tais ídolos e a sua religião.

Como sugere Grunzinski (2003), tendo clareza que a sociedade reproduz, reatualiza e recria o imaginário arcaico a partir das condições particulares da época, o larp blockbuster, transformado em mercadoria e atravessado pela lógica do consumo, pode ser entendido como uma experiência de colonização do imaginário, na medida em que a experiência do larp, antes espontânea, agora, na sua versão colonizada, encontra-se submetida à lógica empresarial, transformando-se em produto para a engenharia da imaginação.

\section{Considerações}

Apropriado pela lógica do consumo, o larp figuraria desprendido de sua potencialidade simbólica. No lugar da criação de narrativas espontâneas, cujo manancial seria o repertório arquetípico dos participantes, o consumo de narrativas derivadas de obras consolidadas pela indústria cultural daria acesso prioritariamente aos conteúdos estereotipados típicos da mediosfera.

Esse processo, nos leva a pensar no interesse do mercado em cooptar tais resistências- afinal, a criatividade parece ser uma das grandes ameaças para o consumo. A invisibilização, como de praxe, comparece como tática de um processo de colonização: mesmo apresentando influências, inspirações e ressonâncias com o larp, o termo em nenhum momento comparece tanto nos empreendimentos e patentes da Disney Enterprises quanto na Escola de Magia e Bruxaria brasileira.

A experiência acumulada de anos de desenvolvimento dos larps parece ter fornecido um significativo arsenal técnico para a sua própria perversão em uma engenharia do imaginário que se propõe a monetizar um entretenimento espontâneo, ao transformá-lo em um produto hipnotizante. Com seu esplendor visual, esses castelos (por vezes literalmente) parecem encarcerar em si não vilões ou bruxos malignos, mas sim a própria capacidade simbólica. 0 que é entregue, em contrapartida, são maravilhas espetaculares que, por mais fascinantes que sejam, são vazias de sentido. O desafio que se abre, e sobre o qual convidamos o debate para encontrar respostas, é como desfazer o feitiço.

\section{Referências}

BOWMAN, S. L. The functions of role-playing games: how participants create community, solve problems and explore identity. Jefferson: MacFarland, 2010. 
BOWMAN, S. L. Imaginação ativa, individuação e narrativas de role-playings. Tríade:

Revista de Comunicação, Cultura e Mídia, São Paulo, v. 5, n. 9, p. 140-157, jun. 2017.

COLLEGE of Wizardry. Larp Tickets. Dziobak Larp Studios, København, 2017

CONTRERA, M. S. Mídia e Pânico: saturação da informação, violência e crise cultural na mídia. São Paulo: Annablume; Fapesp, 2002

CONTRERA, M. S. Mediosfera: meios, imaginário e desencantamento do mundo. Porto Alegre: Imaginalis, 2017. (Série Hermas).

DZIOBAK Larp Studios. 10th Edition College of Wizardry, international school for witches and wizards,Poland, 2016. Disponível em: https://goo.gl/PcwDxG. Acesso em: 04 jul. 2017.

DZIOBAK Larp Studios . About us, København, 2017.

EM CAMPOS do Jordão, 'Hogwarts paulista' terá aulas no mês de agosto. Folha de São Paulo, São Paulo, 2 fev. 2017.

ESCOLA de Magia e Bruxaria do Brasil (EMB). Matrículas, Campos do Jordão, 2017.

FAIRWEATHER Manor. A nordic larp inspired by Downton Abbey, Poland, 2015.

FALCÃO, L. LIVE! Live Action Role Playing: um guia prático para LARP. São Paulo: NpLARP, 2013.

FATLAND, E. On Ripping Off and Selling Out. In: SVANEVIK, M. et al (ed.). Once Upon a Nordic Larp. Oslo: Rollespilsakademiet, 2017, p. 328-333.

FINE, G. A.Shared fantasy: Role Playing Games as Social Worlds. Chicago: The University of Chicago Press, 2002.

FORSTER, Katie. Harry Potter role-playing at real-life Hogwarts. The Guardian, London, 6 Mar. 2016.

FORTUNE \& Felicity - a Jane Austen larp. [s.l.], 2017.

FRANKLIN, Laís. Filme produzido por fãs de Harry Potter ganha aval da Warner. Veja, São Paulo, 3 jun. 2017.

GRUZINSKI, S. A colonização do imaginário: sociedades indígenas e ocidentalização no México espanhol. Séculos XVI - XVIII. São Paulo: Companhia das Letras, 2003.

IUAMA, T. R.. 0 verso da máscara: processos comunicacionais nos larps e RPGs de mesa. Votorantim: Provocare Editora, 2018.

JASPER, Marykate. Disney and Lucasfilm Reveal New Details of Star Wars Land.The Mary Sue, New York, 18 apr., 2017.

JENKINS, H. Cultura da convergência. São Paulo: Aleph, 2009. 
JUNG, C. G. Os arquétipos e o inconsciente coletivo. Petrópolis: Vozes, 2000.

KALAMA, A. K. et al. Role-play simulation engine. Assignee: Disney Enterprises, Inc; Burbank, CA. United States Patent Application Publication US 2013/0066608 A1. 14 mar. 2013. Disponível em: https://goo.gl/r8XjZP. Acesso em: 04 jul. 2017.

KARLSON, Petter. The Monitor Celestra - A Battlestar Galactica inspired frakkin' spaceship larp. Petter Karlsson - Producer and Designer, [s.l.], 19 Mar. 2013.

MIKLOS, J. A construção de vínculos religiosos na cibercultura: a ciber-religião. 2010. 145f. Tese (Doutorado em Comunicação e Semiótica) - Programa de Estudos Pós-Graduados em Comunicação e Semiótica, Pontifícia Universidade Católica de São Paulo, São Paulo, 2010.

MIKLOS, J. Ciber-religião: o sacrifício do corpo na cibercultura. In: BORNHAUSEN, D. A.; MIKLOS, J.; SILVA, M. R. da (org.). CISC 20 anos: comunicação, cultura e mídia. São José do Rio Preto: Bluecom Comunicação, 2012.

MOCHOCKI, M. From College of Wizardry to Witcher School: A Comparative Study of Franchise Larp Design. Homo Ludens, v. 1, n. 9, 2016. Disponível em:

https://bit.ly/31xM84Y, Acesso em: 13 jun. 2019.

MONTOLA, M. Role-Playing as Interactive Construction of Subjective Diegesis. In: GADE, M.; THORUP, L.; SANDER, M. (ed.). As larp grows up: Theory and Methods in Larp. Frederiksberg: Projektgruppen KP03, 2003, p. 82-89.

MONTOLA, M. Social Reality in Roleplaying Games. In: SAITTA, E.; HOLM-ANDERSEN, M.; BACK, J. (ed.). The Foundation Stone of Nordic Larp.Dinamarca: Toptryk Grafisk, 2014, p. 103-112.

MORIN, E. 0 Método 4: As Ideias: habitat, vida, costumes, organização. Porto Alegre: Sulina, 1998.

MORIN, E. Introdução ao pensamento complexo. Porto Alegre, Sulina, 2007.

NEW World Magischola. What is NWM?.Learn Larp, [s.l.], c2017. Disponível em: https://goo.gl/xk2Qfq. Acesso em: 04 jul. 2017.

ÖBERG, Bárbara. Escola de magia brasileira, inspirada em Harry Potter, abre matrículas. Veja, São Paulo, 5 dez. 2016.

PAPERS, H. P.. The Way We Do Business, Workshop '91.Florida: University of Central Florida, 1991. Disponível em: https://goo.gl/qhTyRh. Acesso em: 04 jul. 2017.

PETTERSSON, J. The Necessary Zombie. In: RASSTED, C. (ed.). Talk Larp - Provocative Writings from KP 2011. Copenhagen: Rollespilsakademiet, 2011, p. 124-131.

POHJOLA, M. The Manifesto of the Turku School. In: SAITTA, E.; HOLM-ANDERSEN, M.; BACK, J. (ed.). The Foundation Stone of Nordic Larp. Dinamarca: ToptrykGrafisk, 2014.

RAASTED, C. College of Wizardry - The Magic Continues. Nordic Larp, [s.l.], 2016.

ROWLING, J. K. Harry Potter e o Cálice de Fogo. Rio de Janeiro: Rocco, 2001. 
SAVVAS, G. Disney Parks Imagineers and Lucasfilm Share Details of Their Collaboration on Star Wars-Themed Lands. Disney Parks Blog, [s.l.], 15 apr. 2017.

SILVA, M. C. C. Comunicação e cultura antropofágicas: mídia, corpo e paisagem na eróticopoética oswaldiana. Porto Alegre: Sulina; Sorocaba: EDUNISO, 2007.

SILVA, M. R. da; BAITELLO JUNIOR, N. Vínculos hipnógenos e vínculos culturais nos ambientes da cultura e da comunicação humana. In: ENCONTRO ANUAL DA COMPÓS, 22., 2013, Salvador. Anais [...]. Salvador: Universidade Federal da Bahia, 2013

\title{
Priori Incantatem: a discussion about the Imaginary's colonization in blockbuster larp
}

\begin{abstract}
This article deals with the relationship between larps and Imaginary Studies, especially the ones that have received more media coverage, which can be called blockbuster larps. From this clipping, we discuss a potential Imaginary's colonization by the marketing co-optation of this media. For this, we used mainly the concepts of mediasphere, hypnogenic bonds and the transcendent potential of the communication, through a bibliographical review that dialogues with the case study.
\end{abstract}

\section{Keywords}

Communication. Imaginary. Mediosphere. Case study. Larp.

Recebido em 23/11/2018

Aceito em 10/04/2019 